\title{
Modification of Natural Common Clays as Low Cost Adsorbents for Arsenate Adsorption
}

\author{
Borano Te, Boonchai Wichitsathian, and Chatpet Yossapol
}

\begin{abstract}
In this study, natural common clays were used as raw materials to be modified with ferric and ferrous solutions to develop improved efficient and low cost adsorbents. The adsorbents (Raw Clay, Clay/FeSO 4 , and $\mathrm{Clay} / \mathrm{FeCl}_{3}$ ) were investigated for arsenate removal from synthetic aqueous solution in batch studies with respect to contact time, solution $\mathrm{pH}$, initial $\mathrm{As}(\mathrm{V})$ concentration, and temperature. The results showed that $\operatorname{As}(V)$ uptake was pH dependent and the high efficiency occurred in the acidic condition. The adsorption kinetic data were fitted well with the pseudo second order adsorption model. The estimated maximum adsorption capacity from Langmuir model was $0.44,1.50$, and $0.86 \mathrm{mg} / \mathrm{g}$ for Raw Clay, Clay/ $/ \mathrm{FSO}_{4}$, and Clay/ $/ \mathrm{FCl}_{3}$, respectively. The values of a dimensionless constant separation factor $\left(R_{L}\right)$ and the magnitude of the adsorption intensity $(1 / n)$ showed that $\operatorname{As}(\mathrm{V})$ was adsorbed favorably on all adsorbents. The thermodynamic parameters indicated that the adsorption is spontaneous and endothermic and an irregular increase of the randomness at the adsorbent-adsorbate interface during the adsorption.
\end{abstract}

Index Terms-Natural common clays, adsorbent, adsorption, arsenate.

\section{INTRODUCTION}

Arsenic (As) found in the environment media, in particular in drinking water sources, is one of the major problematic issues for human health due to its toxicity and carcinogenicity [1]. Human health problems associated with excessive and long-term exposure to As are acute and chronic health issues and arsenicosis including skin problems, skin cancers, internal cancers (bladder, kidney and lung), leg and feet blood vessel diseases, and possibly diabetes, high blood pressure, reproductive disorders, adverse pregnancy outcomes, and a decrease in children's intellectual function [2], [3]. More than 70 countries are reported with natural As contamination posing a serious health hazard to an estimated 150 million people, around 110 million of which live in Bangladesh, Cambodia, China, India, Laos, Myanmar, Nepal, Pakistan, Taiwan and Vietnam [4]. European Commission (EC), US Environmental Protection Agency (USEPA), and World Health Organization (WHO) have lowered the permissible limit level of AS in public water supplies to $10 \mathrm{ppb}$ from 50 ppb [5], [6].

Arsenic mostly occurs in the form of arsenate, As(V), and arsenite, As(III). Arsenate generally predominates in

Manuscript received November 24, 2014; revised January 24, 2015. This work was supported in part by the School of Environmental Engineering, Suranaree University of Technology, Thailand.

Borano Te, Boonchai Wichitsathian, and Chatpet Yossapol are with the School of Environmental Engineering, Institute of Engineering, Suranaree University of Technology, Nakhon Ratchasima, Thailand (e-mail: te.borano@yahoo.com, boonchai@sut.ac.th, chatpet@sut.ac.th). oxygen-rich environments like surface water, whereas arsenite is favored and predominates in a moderately reducing environment with anoxic conditions like in anaerobic groundwater [7], [8]. Arsenite can be oxidized to arsenate [9]. Several technologies reported to remove arsenic from water include coagulation-flocculation, ion exchange, membrane technologies, reverse osmosis and adsorption processes [10]. Adsorption is more advantageous over other As removal technologies in terms of simplicity, economy, removal efficiency, easiness in operation and maintenance, flexibility to be scaled up (from the point of use to a municipal water treatment plant), and avoidance of liquid waste generation on site [6], [11], [12]. Low cost materials have gained increasing interest to be used as adsorbents for As removal from water to reduce the operational costs.

Clays have received more attention as the low cost adsorbents in removing water pollutants such as metal ions, organic pollutants and bacteria due to their wide availability, low cost and good adsorption behavior [12]-[14]. Clays are good adsorbents because of their large specific surface area, chemical and mechanical stability, layered structure, and high cation exchange capacity [14], [15]. However, raw clays express low adsorption of some anionic pollutants due to the negative charges on the surface [16]. For instance, clay minerals such as kaolinite, montmorillonite, and illite exhibits arsenate adsorption in the range of 0.15 to $8.4 \mu \mathrm{mol} / \mathrm{g}$, which is much lower than iron containing minerals such as ferrihydrite and goethite possibly adsorbing arsenate in the range of around $200 \mu \mathrm{mol} / \mathrm{g}$ to $700 \mu \mathrm{mol} / \mathrm{g}$ [17]. Thus, raw clays can be modified or bind to other metal ions like irons to improve the adsorption capacity [18], [19]. So far of our knowledge, no study has addressed the use of natural common clays to support iron species to be more cost-effective and efficient adsorbents for arsenate removal from water.

The purpose of this study was to assess the $\mathrm{As}(\mathrm{V})$ adsorption of raw clay and iron modified natural common clays from aqueous solution with respect to contact time, solution $\mathrm{pH}$, initial $\mathrm{As}(\mathrm{V})$ concentration, and temperature, and to evaluate the $\mathrm{As}(\mathrm{V})$ adsorption capacity of raw clay and modified clays under batch experiments. Various models were used to describe and examine the parameters of the kinetic and isotherm experiments. A simple and economic preparation of the iron modified natural common clays was performed. Plus, type of isotherms and thermodynamic parameters for the adsorption were also evaluated.

\section{MATERIALS AND METHODS}

\section{A. Preparation of Adsorbents}

Natural clays in this study were collected from 
North-eastern part of Thailand (Dan Kwian District, Nakhon Ratchasima Province). The samples were cleaned with deionized water (DI water), dried at $104^{\circ} \mathrm{C}$ for $24 \mathrm{~h}$, crushed with mortar and pestle and sieved to achieve the required particle size of less than $75 \mu \mathrm{m}$. The dried clean clays with the desirable particle size were labeled as Raw Clay adsorbent and kept in a dry and clean container for modification process. The modification process was conducted as the following. $20 \mathrm{~g}$ of dried clean clays were added to $200 \mathrm{ml}$ of $0.1 \mathrm{M}$ $\mathrm{FeCl}_{3} \cdot 6 \mathrm{H}_{2} \mathrm{O}$ or $\mathrm{FeSO}_{4} \cdot 7 \mathrm{H}_{2} \mathrm{O}$ solution in a capped $250 \mathrm{ml}$ Erlenmeyer flask. The mixture was shaken on a mechanical shaker with agitation speed of $150 \mathrm{rpm}$ at room temperature for $24 \mathrm{~h}$. Then, the solid was separated from liquid by centrifugation at $3000 \mathrm{rpm}$ for $5 \mathrm{~min}$ and dried at $105{ }^{\circ} \mathrm{C}$ for $24 \mathrm{~h}$. The dried solid was further heated at moderate temperature $\left(300{ }^{\circ} \mathrm{C}\right)$ in a muffle furnace for about $3 \mathrm{~h}$. After cooling down, the particles were washed with DI water until no reddish color or precipitates upon addition of a few drops of 1:10-phenanthroline, and dried at $60^{\circ} \mathrm{C}$ overnight in a hot air flow oven. The final products were labeled as $\mathrm{Clay} / \mathrm{FeCl}_{3}$ and $\mathrm{Clay} / \mathrm{FeSO}_{4}$, respectively, and kept in dry and clean containers for further use.

\section{B. Characterization of Adsorbents}

The elemental composition of Raw Clay was analyzed by Energy Dispersive X-ray Fluorescence (ED-XRF) (XGT-5200 X-ray Analytical Microscope, HORIBA Ltd., Japan). The specific surface area, pore volume, and average pore diameter of the adsorbents were calculated from nitrogen adsorption-desorption isotherm data at $77 \mathrm{~K}$ by the Brunauer-Emmett-Teller (BET) methods using the BET analyzer (BELSORP Mini II, BEL Inc., Japan). Before determining the isotherms, the samples are outgassed by heating at $60^{\circ} \mathrm{C}$ for $24 \mathrm{~h}$ under $\mathrm{N}_{2}$ flow by the pretreatment instrument (BELPREP-vacII, BEL Inc., Japan). The point of zero charge $\left(\mathrm{pH}_{\mathrm{pzc}}\right)$ was evaluated by plotting the initial $\mathrm{pH}$ as a function of the equilibrium $\mathrm{pH}$ (Using $0.01 \mathrm{M} \mathrm{NaCl}$ as background electrolyte with the equilibrium time of $24 \mathrm{~h}$ ) according to the method proposed by [20].

\section{Reagents and Apparatus}

All chemical reagents used in this study were analytical grade, which were purchased from Italmar Co., Ltd., Thailand. The stock solution of $\mathrm{As}(\mathrm{V})$ with concentration of $100 \mathrm{mg} / \mathrm{L}$ was prepared by dissolving sodium hydrogen arsenate $\left(\mathrm{Na}_{2} \mathrm{HAsO}_{4}\right)$ (Sigma-Aldrich chemical) in ultrapure water (resistivity 18.2 M $\Omega$ ) obtained with a Mili-Q water purification system. Arsenate concentrations with further appropriate dilutions were freshly made. Iron solutions for modification were prepared from ferric solution $\left(\mathrm{FeCl}_{3} \cdot 6 \mathrm{H}_{2} \mathrm{O}\right)$ and ferrous solution $\left(\mathrm{FeSO}_{4} \cdot 7 \mathrm{H}_{2} \mathrm{O}\right)$. To prevent chemical interferences, glassware and plastic bottles were washed with DI water and exposed to a $5 \%$ nitric acid solution overnight prior to being used. Adjustment of $\mathrm{pH}$ was done by means of a dilute $\mathrm{HCl}$ or $\mathrm{NaOH}$ solution.

\section{Instrumentals}

The analysis for arsenate concentration was done by inductively coupled plasma-optical emission spectrometry (ICP-OES) (Optima 8000, PerkinElmer, USA) at a wavelength $193.7 \mathrm{~nm}$. The instrument was calibrated by using various standard diluted arsenate stock solutions. The measurement of $\mathrm{pH}$ was made on a $\mathrm{pH}$ meter (Mettler Toledo, Switzerland).

\section{E. Batch Adsorption Studies}

Batch adsorption experiments were carried out at room temperature $\left(25 \pm 1^{\circ} \mathrm{C}\right)$ in acid washed $250 \mathrm{~mL}$ Erlenmeyer flasks or $50 \mathrm{~mL}$ centrifuge tubes. A certain volume of known concentration of $\mathrm{As}(\mathrm{V})$ was mixed with a certain amount of the adsorbents. The mixture was shaken at $150 \mathrm{rpm}$ on a horizontal mechanical shaker (New Brunswick Scientific, Canada) for the equilibrium time. The supernatant was then filtered through $0.22 \mu \mathrm{m}$ syringe filter. The filtrates were stored at $4^{\circ} \mathrm{C}$ until the time for arsenate analyzing by ICP-OES. Blanks (without addition of the adsorbents) were also run at the same condition to determine whether any measureable adsorption of As(V) occurred on the wall of the flasks or tubes. Each experiment was conducted in duplicate and the average of the measurements was calculated. The amount of $\mathrm{As}(\mathrm{V})$ adsorbed per unit mass of the adsorbents, $q_{e}$ $(\mathrm{mg} / \mathrm{g})$, and the percentage of $\mathrm{As}(\mathrm{V})$ adsorbed, $A \%$, were computed respectively using following equations:

$$
\begin{aligned}
& q_{e}=\left(\frac{C_{o}-C_{e}}{M}\right) V \\
& A \%=\left(\frac{C_{o}-C_{e}}{C_{o}}\right) 100
\end{aligned}
$$

where $C_{o}(\mathrm{mg} / \mathrm{L})$ is the initial concentration of arsenate, $C_{e}$ $(\mathrm{mg} / \mathrm{L})$ is the equilibrium concentration of arsenate, $V(\mathrm{~L})$ is the volume of the arsenate solution, and $M(\mathrm{~g})$ is the mass of adsorbents used in the experiments.

\section{F. Effect of $p H$}

The effect of $\mathrm{pH}$ for $\mathrm{As}(\mathrm{V})$ adsorption on the adsorbent was investigated by adjusting the $\mathrm{pH}$ value of the solution from 4 to $11.40 \mathrm{~mL}$ of initial $\mathrm{As}(\mathrm{V})$ concentration of $10 \mathrm{mg} / \mathrm{L}$ and 5 $\mathrm{g} / \mathrm{L}$ of the adsorbent were mixed in the $50 \mathrm{~mL}$ acid washed centrifuge tube. The tubes were shaken on the shaker at agitation speed of $150 \mathrm{rpm}$ and room temperature $\left(25 \pm 1^{\circ} \mathrm{C}\right)$ for the equilibrium time.

\section{G. Kinetic Experiments}

Kinetic experiments were carried out in the acid washed $250 \mathrm{~mL}$ Erlenmeyer flasks with $200 \mathrm{~mL}$ of synthetic $\mathrm{As}(\mathrm{V})$ solution $(10 \mathrm{mg} / \mathrm{L})$ and $10 \mathrm{~g} / \mathrm{L}$ of the adsorbent. During the adsorption, the supernatant samples were taken at fixed time intervals and filtered through $0.22 \mu \mathrm{m}$ syringe filter to analyze for the arsenate concentration. The pseudo first and pseudo second order models were applied to determine the kinetic parameters. These models are represented by the linearized forms as the following:

Pseudo first order model:

$$
\ln \left(q_{e}-q_{t}\right)=-k_{1} t+\ln q_{e}
$$

Pseudo second order model:

$$
\frac{t}{q_{t}}=\frac{1}{q_{e}} t+\frac{1}{k_{2} q_{e}^{2}}
$$


where $q_{e}(\mathrm{mg} / \mathrm{g})$ and $q_{t}(\mathrm{mg} / \mathrm{g})$ are the amount of $\mathrm{As}(\mathrm{V})$ adsorbed at equilibrium and at time $t(\mathrm{~h})$, respectively, and $k_{1}\left(\mathrm{~h}^{-1}\right)$ and $k_{2}\left(\mathrm{~g} \cdot \mathrm{mg}^{-1} \cdot \mathrm{h}^{-1}\right)$ are pseudo first order and pseudo second order kinetic constants, respectively.

\section{H. Isotherm Experiments}

Isotherm experiments were conducted in $50 \mathrm{~mL}$ polyethylene centrifuge tubes with $10 \mathrm{~g} / \mathrm{L}$ of the adsorbents and $40 \mathrm{~mL}$ of $\mathrm{As}(\mathrm{V})$ solution for the equilibrium time. The As(V) concentrations were 1, 5, 10, 20, 30, 40, and $50 \mathrm{mg} / \mathrm{L}$. The supernatant samples were filtered through $0.22 \mu \mathrm{m}$ syringe filter to analyze for the arsenate concentration in the filtrate. Langmuir and Freundlich adsorption models were used for isotherm modeling. These models can be expressed as:

Langmuir model:

$$
\frac{C_{e}}{q_{e}}=\frac{1}{q_{m}} C_{e}+\frac{1}{K_{L} q_{m}}
$$

Freundlich model:

$$
\ln q_{e}=\ln K_{f}+\frac{1}{n} \ln C_{e}
$$

where $q_{m}(\mathrm{mg} / \mathrm{g})$ is the maximum amount of $\mathrm{As}(\mathrm{V})$ adsorbed at equilibrium, $K_{L}(\mathrm{~L} / \mathrm{mg})$ is the Langmuir constant, and $K_{f}$ $\left(\mathrm{mg}^{1-n} \mathrm{~g}^{-1} \mathrm{~L}^{n}\right)$ and $n$ are the Freundlich constants related to adsorption capacity and adsorption intensity of adsorbent, respectively.

\section{Effect of Temperature}

The effect of temperature for $\mathrm{As}(\mathrm{V})$ adsorption on the adsorbent was investigated in $250 \mathrm{~mL}$ Erlenmeyer flasks with $50 \mathrm{~mL}$ of synthetic As(V) solution $(10 \mathrm{mg} / \mathrm{L})$ and $10 \mathrm{~g} / \mathrm{L}$ of the adsorbents. The flasks were shaken on the shaker at agitation speed of $150 \mathrm{rpm}$ for the equilibrium time. The temperatures were $35,45,55$, and $65^{\circ} \mathrm{C}$. The thermodynamic parameters of the adsorption were calculated using the following equations:

$$
\begin{aligned}
\Delta G^{0} & =-R T \ln K_{d} \\
\ln \mathrm{K}_{d} & =-\frac{\Delta H^{0}}{R T}+\frac{\Delta S^{0}}{R} \\
\Delta S^{0} & =\frac{\Delta H^{0}-\Delta G^{0}}{T}
\end{aligned}
$$

where $\Delta G^{\circ}$ is the Gibbs free energy change $(\mathrm{kJ} / \mathrm{mol}), \Delta H^{\circ}$ is the standard enthalpy change $(\mathrm{kJ} / \mathrm{mol}), \Delta S^{\circ}$ is the standard entropy change $(\mathrm{J} / \mathrm{mol} \mathrm{K}), T$ is the absolute temperature $(\mathrm{K})$, $R$ is the universal gas constant $(8.314 \mathrm{~J} / \mathrm{mol} \mathrm{K}) . K_{d}(\mathrm{~L} / \mathrm{g})$ is the equilibrium constant defined by $\mathrm{As}(\mathrm{V})$ adsorbed at equilibrium $\left(q_{e}\right)$ over $\mathrm{As}(\mathrm{V})$ concentration at equilibrium $\left(C_{e}\right)$ [21].

\section{RESULTS AND DISCUSSION}

\section{A. Properties of Adsorbent}

The physical chemical properties of the adsorbents were presented in Table I. The chemical compositions of natural common clay for further modification were: $\mathrm{Al}_{2} \mathrm{O}_{3}(25.26 \%)$, $\mathrm{SiO}_{2}$ (66.86\%), $\mathrm{K}_{2} \mathrm{O}$ (1.48\%), $\mathrm{CaO}$ (0.52\%), $\mathrm{TiO}_{2}(1.04 \%)$, $\mathrm{MnO}_{2}(0.05 \%)$, and $\mathrm{Fe}_{2} \mathrm{O}_{3}(5.29 \%)$. The analysis revealed that the major constituents were $\mathrm{SiO}_{2}$ and $\mathrm{Al}_{2} \mathrm{O}_{3}$, followed by $\mathrm{Fe}_{2} \mathrm{O}_{3}$. From the BET analysis, the surface area of Raw Clay, Clay/ $/ \mathrm{FeSO}_{4}$, and $\mathrm{Clay} / \mathrm{FeCl}_{3}$ were 52.45, 51.00, and $52.08 \mathrm{~m}^{2} / \mathrm{g}$, respectively. Clay/ $/ \mathrm{FeSO}_{4}$ had highest values of average pore diameter $(6.25 \mathrm{~nm})$, followed by $\mathrm{Clay} / \mathrm{FeCl}_{3}$ $(6.14 \mathrm{~nm}) . \mathrm{pH}_{\mathrm{pzc}}$ was 5.90, 4.20, and 4.40 for Raw Clay, Clay $/ \mathrm{FeSO}_{4}$, and $\mathrm{Clay} / \mathrm{FeCl}_{3}$, respectively.

TABLE I: PHYSICAL-CHEMICAL PROPERTIES OF THE ADSORBENTS

\begin{tabular}{cccc}
\hline \hline Properties & Raw Clay & Clay/FeSO & Clay/FeCl $_{3}$ \\
\hline Surface area, $\mathrm{S}_{\mathrm{BET}}\left(\mathrm{m}^{2} / \mathrm{g}\right)$ & 52.45 & 51.00 & 52.08 \\
Total pore volume $\left(\mathrm{cm}^{3} / \mathrm{g}\right)$ & 0.075 & 0.079 & 0.080 \\
Mean pore diameter $(\mathrm{nm})$ & 5.76 & 6.25 & 6.14 \\
Point of zero charge $\left(\mathrm{pH}_{\mathrm{pzc})}\right.$ & 5.90 & 4.20 & 4.40 \\
\hline \hline
\end{tabular}

\section{B. Effect of $p H$}

Arsenate species and the surface charge of the adsorbent in aqueous solution are $\mathrm{pH}$ dependent, which make $\mathrm{pH}$ be one of the most important factors affecting arsenate adsorption onto the adsorbent in the liquid phase [22]. The effect of $\mathrm{pH}$ on arsenate adsorption onto raw clay and modified clays is shown in Fig. 1. It was found that arsenate adsorption onto all adsorbents was $\mathrm{pH}$ dependent and the maximum adsorption occurred at lower $\mathrm{pH}$ values. The adsorption efficiency for all adsorbents decreased with the increase of the initial $\mathrm{pH}$, and sharply decreased when the initial $\mathrm{pH}$ is above 10 .

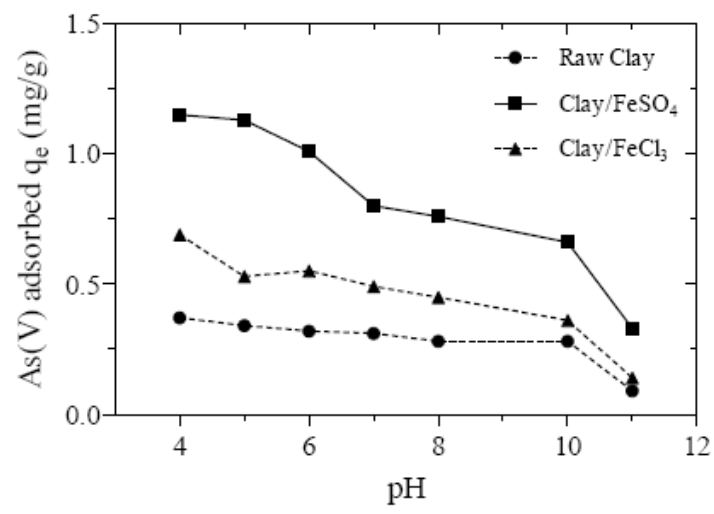

Fig. 1. Effect of $\mathrm{pH}$ on the $\mathrm{As}(\mathrm{V})$ adsorption onto Raw Clay, Clay/FeSO 4 , and $\mathrm{Clay} / \mathrm{FeCl}_{3}$.

Arsenate species in aqueous phase exist mainly as $\mathrm{H}_{3} \mathrm{AsO}_{4}$ at $\mathrm{pH}$ less than 2.2, $\mathrm{H}_{2} \mathrm{AsO}_{4}{ }^{-}$at $\mathrm{pH}$ between 2.2 and 6.98, $\mathrm{HAsO}_{4}{ }^{2-}$ at $\mathrm{pH}$ between 6.98 and 11.5, and $\mathrm{AsO}_{4}{ }^{3-}$ at $\mathrm{pH}$ above 11.5. The surface charge of the adsorbents becomes more positively charged when $\mathrm{pH}$ is less than $\mathrm{pH}_{\mathrm{pzc}}$ and more negatively charged when $\mathrm{pH}$ is above $\mathrm{pH}_{\mathrm{pzc}}$ [22]. A better performance of the adsorption occurred at acidic condition can be interpreted that the more positive charge of the adsorbents $\left(\mathrm{pH}<\mathrm{pH}_{\mathrm{pzc}}\right)$ provided more adsorption sites for the predominant arsenate species $\left(\mathrm{H}_{2} \mathrm{AsO}_{4}^{-}\right.$or $\left.\mathrm{HAsO}_{4}^{-}\right)$. When $\mathrm{pH}$ increased to higher than $\mathrm{pH}_{\mathrm{pzc}}$, repulsive force between the adsorbents and the adsorbate has increased resulting in decreasing $\mathrm{As}(\mathrm{V})$ uptake from the solution. Therefore, $\mathrm{pH}$ values have impact on arsenate adsorption due to the change of the electrostatic force between arsenate species and the 
adsorbents.

\section{Kinetic Studies}

The plots of the amount of $\mathrm{As}(\mathrm{V})$ adsorbed versus contact time are given in Fig. 2. The results showed that $\mathrm{As}(\mathrm{V})$ adsorption was fast within the first hour of agitation time and slow afterwards until equilibrium. The rapid uptake of $\mathrm{As}(\mathrm{V})$ within the first hour was due to the more presence of competent active adsorbing sites on the surface of the adsorbent at the initial stage of the contact time. Equilibrium time was achieved within $24 \mathrm{~h}$, and was used for other experiments.

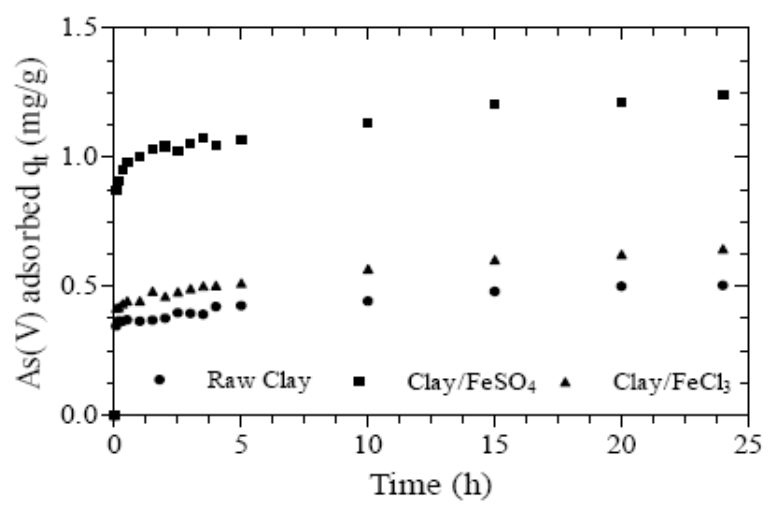

Fig. 2. Effect of contact time on the As(V) adsorption onto Raw Clay, Clay/ $/ \mathrm{FeSO}_{4}$, and Clay/ $\mathrm{FeCl}_{3}$.

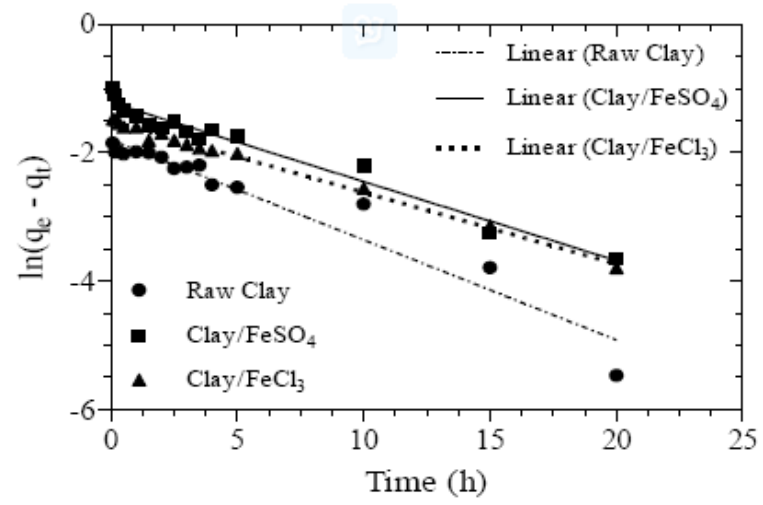

Fig. 3. Pseudo first order kinetics for the $\mathrm{As}(\mathrm{V})$ adsorption on Raw Clay, $\mathrm{Clay} / \mathrm{FeSO}_{4}$, and $\mathrm{Clay} / \mathrm{FeCl}_{3}$.

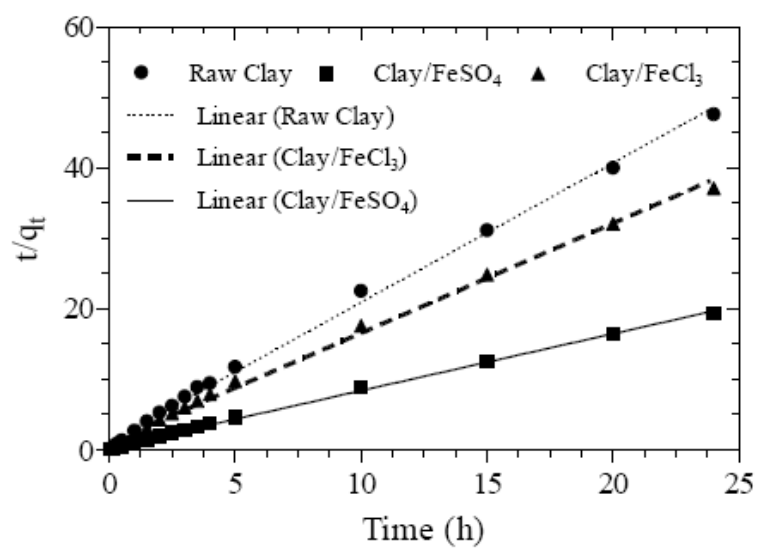

Fig. 4. Pseudo second order kinetics for the As(V) adsorption on Raw Clay, $\mathrm{Clay} / \mathrm{FeSO}_{4}$, and $\mathrm{Clay} / \mathrm{FeCl}_{3}$.

The kinetic data on arsenate adsorption to the adsorbents were modeled by the pseudo first order and the pseudo second order models. The rate constant $\left(k_{1}\right)$ and calculated equilibrium capacity $\left(q_{e, c a l}\right)$ of the pseudo first order models were determined from the plot of $\ln \left(q_{e}-q_{t}\right)$ versus $t$ (Fig. 3). The rate constant $\left(k_{2}\right)$ and calculated equilibrium capacity $\left(q_{e, c a l}\right)$ of the pseudo second order models were determined from the plot of $t / q_{t}$ versus $t$ (Fig. 4). Kinetic parameters of the pseudo first order and pseudo second order models are given in Table II.

The values of correlation coefficient $\left(R^{2}\right)$ of the adsorbents (Raw Clay, Clay/FeSO 4 and Clay/ $/ \mathrm{FeCl}_{3}$ were 0.9298, 0.9698, and 0.9916 , respectively) for the pseudo first order adsorption model are lower than those of the adsorbents (Raw Clay, Clay/ $/ \mathrm{FSO}_{4}$ and $\mathrm{Clay} / \mathrm{FeCl}_{3}$ were $0.9969,0.9987$, and 0.9963, respectively) for the pseudo second order model.

TABLE II: KINETIC PARAMETERS FOR As(V) ADSORPTION ON DIFFERENT

\begin{tabular}{cccc}
\multicolumn{3}{c}{ ADSORBENTS } \\
\hline \hline & Raw Clay & Clay/FeSO & Clay/FeCl $_{3}$ \\
\hline$q_{e, \text { exp }}(\mathrm{mg} / \mathrm{g})$ & 0.504 & 1.230 & 0.650 \\
Pseudo first order & & & \\
$q_{e, \text { cal }}(\mathrm{mg} / \mathrm{g})$ & 0.170 & 0.306 & 0.221 \\
$k_{1}\left(\mathrm{~h}^{-1}\right)$ & 0.1580 & 0.1609 & 0.1111 \\
$R^{2}$ & 0.9298 & 0.9698 & 0.9916 \\
Pseudo second order & & & \\
$q_{e, \text { cal }}(\mathrm{mg} / \mathrm{g})$ & 0.506 & 1.231 & 0.6422 \\
$k_{2}\left(\mathrm{~g} \cdot \mathrm{mg}^{-1} \mathrm{~h}^{-1}\right)$ & 3.4730 & 2.2140 & 2.4820 \\
$\mathrm{R}^{2}$ & 0.9969 & 0.9987 & 0.9963 \\
\hline \hline
\end{tabular}

Additionally, theoretical or experimental values $\left(q_{e, \text { exp }}\right)$ of the adsorbents (Raw Clay, Clay/ $\mathrm{FeSO}_{4}$ and $\mathrm{Clay} / \mathrm{FeCl}_{3}$ were $0.504,1.230$, and $0.650 \mathrm{mg} / \mathrm{g}$, respectively) obtained from the pseudo second order are in a good accordance with the calculated equilibrium adsorption capacity $\left(q_{e, c a l}\right)$ of the adsorbents (Raw Clay, Clay/ $/ \mathrm{FeSO}_{4}$ and $\mathrm{Clay} / \mathrm{FeCl}_{3}$ were $0.506,1.231$, and $0.642 \mathrm{mg} / \mathrm{g}$, respectively). Therefore, the arsenate adsorption onto the studied adsorbents followed the pseudo second order adsorption model.

\section{Isotherm Studies}

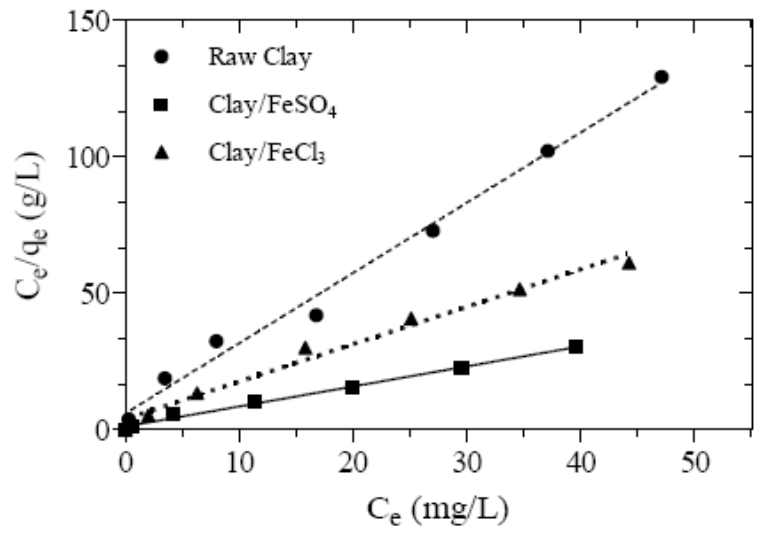

Fig. 5. Langmuir plot for the As(V) adsorption on Raw Clay, Clay/FeSO and $\mathrm{Clay} / \mathrm{FeCl}_{3}$.

The Langmuir and Freundlich models were used to analyze the isotherm data. For the Langmuir model, $q_{m}(\mathrm{mg} / \mathrm{g})$ and $K_{L}(\mathrm{~L} / \mathrm{mg})$ were computed from the slope and intercept of the plot $C_{e} / q_{e}$ versus $C_{e}$, respectively (Fig. 5). For the Freundlich model, $1 / n$ and $K_{f}\left(\mathrm{mg}^{1-n} \mathrm{~g}^{-1} \mathrm{~L}^{n}\right)$ were obtained from the slope and intercept of the plot $\ln q_{e}$ and $\ln C_{e}$, respectively (Fig. 6). Values of the isotherm parameters are presented in Table III. Raw Clay and $\mathrm{Clay} / \mathrm{FeSO}_{4}$ were well described by the 
Langmuir model with correlation coefficients $\left(R^{2}\right) 0.9903$ and 09932, respectively. Clay/ $\mathrm{FeCl}_{3}$ was fitted well to the Freundlich model with correlation coefficient $\left(R^{2}\right) 0.9922$. The estimated maximum adsorption capacity was $0.44,1.50$, and $0.86 \mathrm{mg} / \mathrm{g}$ for Raw Clay, Clay/ $\mathrm{FeSO}_{4}$, and $\mathrm{Clay} / \mathrm{FeCl}_{3}$, respectively. The nature of adsorption isotherm can be predicted by evaluating the essential characteristic of the Langmuir isotherm expressed in terms of a dimensionless constant separation factor, $R_{L}$. The separation factor was computed by $R_{L}=1 /\left(1+K_{L} C_{o}\right)$, where $C_{o}(\mathrm{mg} / \mathrm{L})$ is the initial $\mathrm{As}(\mathrm{V})$ concentration.

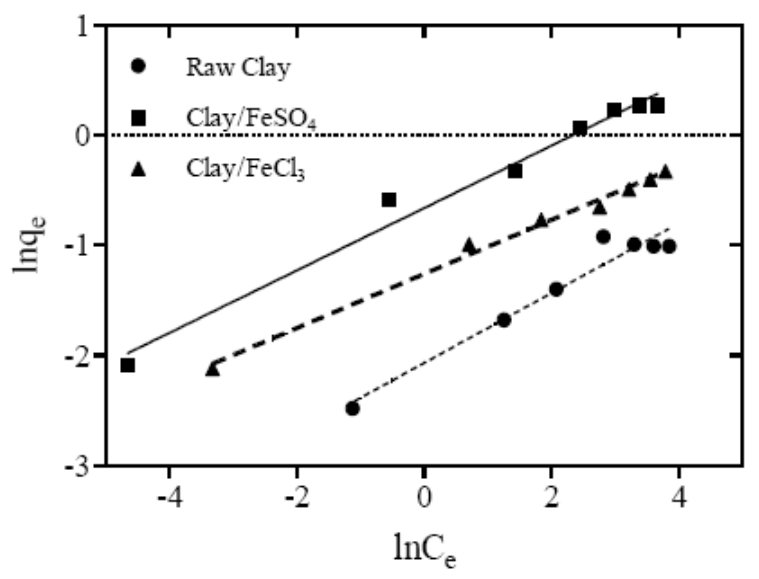

Fig. 6. Freundlich plot for the $\mathrm{As}(\mathrm{V})$ adsorption on Raw Clay, $\mathrm{Clay} / \mathrm{FeSO}_{4}$, and $\mathrm{Clay} / \mathrm{FeCl}_{3}$.

TABLE III: CALCULATED ADSORPTION ISOTHERM PARAMETERS

\begin{tabular}{cccc}
\hline \hline Model & Raw Clay & Clay/FeSO & $\mathrm{Clay} / \mathrm{FeCl}_{3}$ \\
\hline Langmuir & & & \\
$q_{m}(\mathrm{mg} / \mathrm{g})$ & 0.44 & 1.50 & 0.86 \\
$K_{L}\left(\mathrm{Lmg}^{-1}\right)$ & 0.3830 & 0.5210 & 0.2946 \\
$\mathrm{R}_{\mathrm{L}}$ & $0.05-0.72$ & $0.04-0.66$ & $0.06-0.77$ \\
$\mathrm{R}^{2}$ & 0.9903 & 0.9932 & 0.9835 \\
Freundlich & & & \\
$K_{f}$ & 0.1126 & 0.5150 & 0.2800 \\
$1 / n$ & 0.32 & 0.28 & 0.25 \\
$\mathrm{R}^{2}$ & 0.9728 & 0.9806 & 0.9922 \\
\hline \hline
\end{tabular}

The adsorption process is irreversible if $R_{L}=0$, favorable if $0<R_{L}<1$, linear if $R_{L}=1$ and unfavorable if $R_{L}=1$ [15]. The values of $R_{L}$ computed for $\mathrm{As}(\mathrm{V})$ adsorption on Raw Clay, Clay/ $/ \mathrm{FeSO}_{4}$, and Clay/ $\mathrm{FeCl}_{3}$ were $0.05-0.72,0.04-0.66$, and $0.06-0.77$, respectively. The obtained values of $\mathrm{R}_{\mathrm{L}}$ are within the range of $0-1$, which indicated that the favorable equilibrium $\mathrm{As}(\mathrm{V})$ adsorption occurred for all adsorbents. Similarly, the magnitude of the adsorption intensity, $1 / n$, can suggest the type of isotherm from the Freundlich model. The adsorption is favorable when $0<1 / n<1$, irreversible when $1 / n=1$ and unfavorable when $1 / n>1$ [1]. The values of $1 / n$ obtained from the equilibrium adsorption of $\mathrm{As}(\mathrm{V})$ were 0.32 , 0.28 , and 0.25 for Raw Clay, Clay/ $/ \mathrm{FSO}_{4}$, and $\mathrm{Clay} / \mathrm{FeCl}_{3}$, respectively, which fell within the range of $0-1$. Therefore, $\mathrm{As}(\mathrm{V})$ was adsorbed favorably on all adsorbents.

\section{E. Thermodynamic Parameters}

The equilibrium constant values, $K_{d}$, for $\mathrm{As}(\mathrm{V})$ adsorption on the adsorbent were calculated at different temperatures $(308,318,328$, and $338 \mathrm{~K})$ by dividing $q_{e}$ with $C_{e}$. These values were used to calculate the thermodynamic parameters.
The $\Delta H^{\circ}$ value was determined from the slope of the linear plot of $\ln K_{d}$ versus $1 / T$, as shown in Fig. 7. The values of thermodynamic parameters for the adsorption of $\mathrm{As}(\mathrm{V})$ were presented in Table IV. Gibbs free energy change $\left(\Delta G^{\circ}\right)$ was found to be negative in values while both standard enthalpy change $\left(\Delta H^{\circ}\right)$ and standard entropy change $\left(\Delta S^{\circ}\right)$ were found to be positive. References [21]-[24] suggested that the negative values of $\Delta G^{\circ}$ and the positive of $\Delta H^{\circ}$ indicate the adsorption is spontaneous and endothermic, and positive $\Delta S^{\circ}$ value of the adsorption process indicates an increase of the randomness at the adsorbent-adsorbate interface during the adsorption.

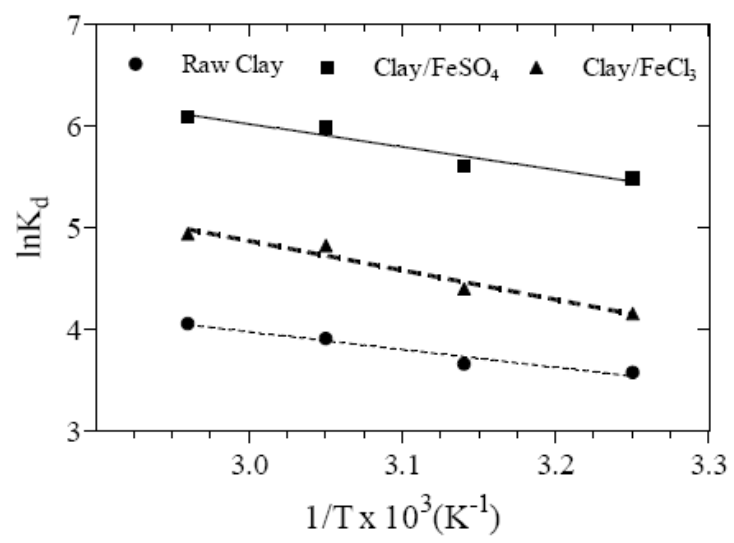

Fig. 7. The plot of $\ln K_{d}$ versus $1 / T$ for the As(V) adsorption on Raw Clay, $\mathrm{Clay} / \mathrm{FeSO}_{4}$, and $\mathrm{Clay} / \mathrm{FeCl}_{3}$.

TABLE IV: THERMODYNAMIC PARAMETERS FOR THE A(V) ADSORPTION ONTO RAW CLAY AND MODIFIED CLAY ADSORBENTS

\begin{tabular}{ccccc}
\hline \hline $\mathrm{T}(\mathrm{K})$ & $\ln K_{d}$ & $\Delta G^{\circ}(\mathrm{kJ} / \mathrm{mol})$ & $\Delta H^{\circ}(\mathrm{kJ} / \mathrm{mol})$ & $\Delta S^{\circ}(\mathrm{J} / \mathrm{molK})$ \\
\hline Raw Clay & & & & \\
308 & 3.58 & -9.16 & +14.48 & +76.78 \\
318 & 3.66 & -9.68 & & +75.99 \\
328 & 3.91 & -10.67 & & +76.68 \\
338 & 4.06 & -11.40 & & +76.59 \\
Clay/FeSO$_{4}$ & & & & \\
308 & 5.49 & -14.05 & +18.75 & +106.50 \\
318 & 5.61 & -14.85 & & +105.64 \\
328 & 5.99 & -16.34 & & +106.97 \\
338 & 6.09 & -17.12 & & +106.14 \\
Clay/FeCl 3 & & & & +112.32 \\
308 & 4.16 & -10.64 & +23.95 & +111.93 \\
318 & 4.40 & -11.64 & & +113.18 \\
328 & 4.83 & -13.17 & & +111.91 \\
338 & 4.94 & -13.87 & & \\
\hline \hline
\end{tabular}

\section{CONCLUSION}

Natural common clays, low cost materials and widely available, can be modified with ferric and ferrous solutions to be the adsorbents for arsenate removal from water. The modification is cheap and simple process. Compared with raw clay's arsenate uptake, iron modification process has effect on the arsenate adsorption efficiency from a synthetic aqueous solution. The ferric solution has increased the uptake efficiency two times, and the ferrous solution has increased efficiency three folds. Arsenate adsorption by modified adsorbents, both Clay/ $/ \mathrm{FeSO}_{4}$ and Clay $/ \mathrm{FeCl}_{3}$, is affected by $\mathrm{pH}$ values of the solution. Therefore, natural clays can be used to support iron species solutions to be low cost and more 
efficient adsorbents for arsenate removal from water. However, further studies should be considered before the adsorbents can be applied in the arsenic contaminated areas to supply safe drinking water. The studies may involve the effect of various minerals (Chloride, sulfate, phosphate, which are mostly found in the natural water), and the performance of the adsorbents in the column.

\section{ACKNOWLEDGMENT}

This study was supported by SUT-ASEAN Scholarship program, the Center for Scientific and Technological Equipment, and School of Environmental Engineering, Institute of Engineering, Suranaree University of Technology, Nakhon Ratchasima, Thailand.

\section{REFERENCES}

[1] F. Fufa, E. Alemayehu, and B. Lennartz, "Sorptive removal of arsenate using termite mound," J. Environ. Manage., vol. 132, pp. 188-196, 2014.

[2] A. K. Sharma, J. C. Tjell, J. J. Sloth, and P. E. Holm, "Review of arsenic contamination, exposure through water and food and low cost mitigation options for rural areas," Applied Geochemistry, vol. 41, pp. 11-33, 2014.

[3] Y. Chen, F. Parvez, M. Gamble, T. Islam, A. Ahmed, M. Argos, J. H. Graziano, and H. Ahsan, "Arsenic exposure at low-to-moderate levels and skin lesions, arsenic metabolism, neurological functions, and biomarkers for respiratory and cardiovascular diseases: Review of recent findings from the health effects of arsenic longitudinal study (HEALS) in Bangladesh," Toxicol. Appl. Pharmacol., vol. 239, pp. 184-192, 2009.

[4] H. Brammer and P. Ravenscroft, "Arsenic in groundwater: a threat to sustainable agriculture in South and South-east Asia," Environ. Int., vol. 35, pp. 647-654, 2009

[5] S. Luther, N. Borgfeld, J. Kim, and J. G. Parsons, "Removal of arsenic from aqueous solution: A study of the effects of $\mathrm{pH}$ and interfering ions using iron oxide nanomaterials," Microchemical Journal, vol. 101, pp. 30-36, 2012.

[6] D. Masih, Y. Izumi, K. Aika, and Y. Seida, "Optimization of an iron intercalated montmorillonite preparation for the removal of arsenic at low concentrations," Engineering in Life Sciences, vol. 7, pp. 52-60, 2007.

[7] I. Villaescusa and J. C. Bollinger, "Arsenic in drinking water: sources, occurrence and health effects (a review)," Reviews in Environmental Science and Bio/Technology, vol. 7, pp. 307-323, 2008.

[8] S. Wang and C. N. Mulligan, "Occurrence of arsenic contamination in Canada: sources, behavior and distribution," Sci. Total Environ., vol. 366, pp. 701-21, 2006.

[9] P. Mondal, S. Bhowmick, D. Chatterjee, A. Figoli, and B. Van der Bruggen, "Remediation of inorganic arsenic in groundwater for safe water supply: A critical assessment of technological solutions," Chemosphere, vol. 92, pp. 157-170, 2013.

[10] A. V. Vitela-Rodriguez and J. R. Rangel-Mendez, "Arsenic removal by modified activated carbons with iron hydro(oxide) nanoparticles," $J$. Environ. Manage., vol. 114, pp. 225-231, 2013.

[11] P. Sabbatini, F. Yrazu, F. Rossi, G. Thern, A. Marajofsky, and M. M. F. de Cortalezzi, "Fabrication and characterization of iron oxide ceramic membranes for arsenic removal," Water Res., vol. 44, pp. 5702-12, 2010.

[12] B. Dousova, T. Grygar, A. Martaus, L. Fuitova, D. Kolousek, and V. Machovic," Sorption of As(V) on aluminosilicates treated with Fe(II) nanoparticles," J. Colloid. Interface Sci., vol. 302, pp. 424-431, 2006.

[13] A. Zehhaf, A. Benyoucef, C. Quijada, S. Taleb, and E. Morallón, "Algerian natural montmorillonites for arsenic(III) removal in aqueous solution," International Journal of Environmental Science and Technology, 2013.

[14] A. Ramesh, H. Hasegawa, T. Maki, and K. Ueda, "Adsorption of inorganic and organic arsenic from aqueous solutions by polymeric $\mathrm{Al} / \mathrm{Fe}$ modified montmorillonite," Separation and Purification Technology, vol. 56, pp. 90-100, 2007.

[15] A. Sdiri, T. Higashi, T. Hatta, F. Jamoussi, and N. Tase, "Evaluating the adsorptive capacity of montmorillonitic and calcareous clays on the removal of several heavy metals in aqueous systems," Chemical Engineering Journal, vol. 172, pp. 37-46, 2011.

[16] X. Ren, Z. Zhang, H. Luo, B. Hu, Z. Dang, C. Yang, and L. Li, "Adsorption of arsenic on modified montmorillonite," Applied Clay Science, vol. 97-98, pp. 17-23, 2014.

[17] C. Luengo, V. Puccia, and M. Avena, "Arsenate adsorption and desorption kinetics on a Fe(III)-modified montmorillonite," J. Hazard Mater., vol. 186, pp. 1713-1719, 2011.

[18] M. Q. Jiang, Q. P. Wang, X. Y. Jin, and Z. L. Chen, "Removal of Pb(II) from aqueous solution using modified and unmodified kaolinite clay," J. Hazard Mater., vol. 170, pp. 332-339, 2009.

[19] D. Mohapatra, D. Mishra, G. R. Chaudhury, and R. P. Das, "Arsenic(V) adsorption mechanism using kaolinite, montmorillonite and illite from aqueous medium," J. Environ. Sci. Health A Tox Hazard Subst. Environ. Eng., vol. 42, pp. 463-469, 2007.

[20] J. Su, H. G. Huang, X. Y. Jin, X. Q. Lu, and Z. L. Chen, "Synthesis, characterization and kinetic of a surfactant-modified bentonite used to remove $\mathrm{As}(\mathrm{III})$ and $\mathrm{As}(\mathrm{V})$ from aqueous solution," J. Hazard Mater., vol. 185 , pp. $63-70,2011$.

[21] S. M. Al-Rashed and A. A. Al-Gaid, "Kinetic and thermodynamic studies on the adsorption behavior of Rhodamine B dye on Duolite C-20 resin," Journal of Saudi Chemical Society, vol. 16, pp. 209-215, 2012.

[22] Q. Chang, W. Lin, and W. C. Ying, "Preparation of iron-impregnated granular activated carbon for arsenic removal from drinking water," $J$. Hazard Mater., vol. 184, pp. 515-522, 2010.

[23] T. Sumathi and G. Alagumuthu, "Adsorption Studies for Arsenic Removal Using Activated Moringa oleifera," International Journal of Chemical Engineering, vol. 2014, pp. 1-6, 2014.

[24] F. Zha, W. Huang, J. Wang, Y. Chang, J. Ding, and J. Ma, "Kinetic and thermodynamic aspects of arsenate adsorption on aluminum oxide modified palygorskite nanocomposites," Chemical Engineering Journal, vol. 215-216, pp. 579-585, 2013.

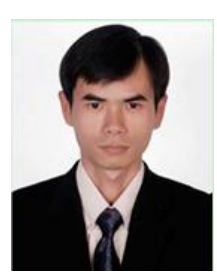

Borano Te was born in Kampong Cham, Cambodia on December 12, 1987. He obtained a b achelor degree of technology in civil construction from Preah Kossomak Polytechnic Institute, Phnom Penh, Cambodia in 2008 In 2010, he graduated with a bachelor degree of science in environmental science from Pannasastra University of Cambodia, Phnom Penh, Cambodia. In 2012, he won a SUT-ASEAN PhD Scholarship program to pursue a graduate study at Suranaree University of Technology (SUT), Nakhon Ratchasima, Thailand. Now, he is a PhD student at SUT. His research interest is the arsenic removal from aqueous solution using clays and modified clays.

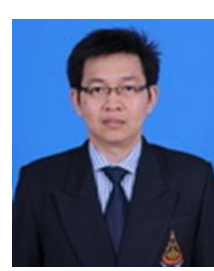

Boonchai Wichitsathian was born in Bangkok, Thailand. He obtained a bachelor degree of industrial chemistry and a master degree of environmental technology from King Mongkut's Institute of Technology Thonburi (KMITT), Bangkok, Thailand. He earned his degree of doctor of technical science in environmental technology and management from Asian Institute of Technology (AIT) under scholarship of Royal Thai Government. Now, he is a lecturer in the School of Environmental Engineering, and a director of the Center for Cooperative Education and Career Development, Suranaree University of Technology, Thailand.

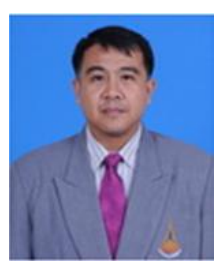

Chatpet Yassopol was born in Naknon Ratchasima, Thailand. He received his bachelor degree of engineering in environmental engineering from Khon Kaen University, Thailand and master degree of engineering in environmental engineering from Chulalongkorn University, Bangkok, Thailand. $\mathrm{He}$ earned his Ph.D. degree in environmental engineering from New Jersey Institute of Technology, USA. In the present, he holds a position as a lecturer in the School of Environmental Engineering, as a deputy director of the Center of Scientific and Technological Equipment, and as the head of Suranaree Environmental Technology Research and Consulting Unit, Suranaree University of Technology, Thailand. 